\title{
Comparative preoperative characteristics and postoperative outcomes at a private versus a safety-net hospital following endoscopic endonasal transsphenoidal resection of pituitary adenomas
}

\author{
Janelle Cyprich, BS, ${ }^{1}$ Dhiraj J. Pangal, BS, ${ }^{1}$ Martin Rutkowski, MD, ${ }^{1}$ Daniel A. Donoho, MD, ${ }^{1}$ \\ Mark Shiroishi, MD, ${ }^{2}$ Chia-Shang Jason Liu, MD, PhD, ${ }^{2}$ John D. Carmichael, MD, ${ }^{3,4}$ and \\ Gabriel Zada, MD, MS $\mathbf{S}^{1,4}$
}

1Department of Neurosurgery, 2Division of Neuroradiology, Department of Radiology, and ${ }^{3}$ Division of Endocrinology, Department of Medicine, Keck School of Medicine, University of Southern California; and ${ }^{4}$ USC Pituitary Center, Los Angeles, California

\begin{abstract}
OBJECTIVE Sociodemographic disparities in health outcomes are well documented, but the effects of such disparities on preoperative presentation of pituitary adenomas $(\mathrm{PA})$ and surgical outcomes following resection are not completely understood. In this study the authors sought to compare the preoperative clinical characteristics and postoperative outcomes in patients undergoing PA resection at a private hospital $(\mathrm{PH})$ versus a safety-net hospital (SNH).

METHODS The authors conducted a retrospective review over a 36-month period of patients with PAs who underwent endoscopic endonasal transsphenoidal surgery performed by the same attending neurosurgeon at either a $\mathrm{PH}$ or an $\mathrm{SNH}$ at a single academic medical institution.

RESULTS A total of $92 \mathrm{PH}$ patients and $69 \mathrm{SNH}$ patients were included. SNH patients were more likely to be uninsured or have Medicaid $(88.4 \%$ vs $10.9 \%, p<0.0001)$. A larger percentage of SNH patients were Hispanic ( $98.7 \%$ vs $32.6 \% \mathrm{p}$ $<0.0001)$, while PH patients were more likely to be non-Hispanic white $(39.1 \%$ vs $4.3 \%, p<0.0001)$. SNH patients had a larger mean PA diameter (26.2 vs $22.4 \mathrm{~mm}, p=0.0347)$ and a higher rate of bilateral cavernous sinus invasion $(13 \%$ vs $4.3 \%, p=0.0451)$. SNH patients were more likely to present with headache $(68.1 \%$ vs $45.7 \%, p=0.0048)$, vision loss $(63.8 \%$ vs $35.9 \%, p<0.0005)$, panhypopituitarism ( $18.8 \%$ vs $4.3 \%, p=0.0031)$, and pituitary apoplexy $(18.8 \%$ vs $7.6 \%$, $p=0.0334)$. Compared to PH patients, SNH patients were as likely to undergo gross-total resection $(73.9 \%$ vs $76.1 \%$, $p=0.7499)$ and had similar rates of postoperative improvement in headache $(80 \%$ vs $89 \%, p=0.14)$ and vision $(82 \%$ vs $84 \%, p=0.74$ ), but had higher rates of postoperative panhypopituitarism ( $23 \%$ vs $10 \%, p=0.04$ ) driven by preoperative endocrinopathies. Although there were no differences in tumor recurrence or progression, loss to follow-up was seen in $7.6 \%$ of $\mathrm{PH}$ versus $18.6 \%(p=0.04)$ of SNH patients.
\end{abstract}

CONCLUSIONS Patients presenting to the SNH were more often uninsured or on Medicaid and presented with larger, more advanced pituitary tumors. SNH patients were more likely to present with headaches, vision loss, and apoplexy, likely translating to greater improvements in headache and vision observed after surgery. These findings highlight the association between medically underserved populations and more advanced disease states at presentation, and underscore the likely role of academic tertiary multidisciplinary care teams and endoscopic PA resection in somewhat mitigating sociodemographic factors known to portend poorer outcomes, though longer-term follow-up is needed to confirm these findings.

https://thejns.org/doi/abs/10.3171/2019.12.JNS192506

KEYWORDS adenoma; transsphenoidal resection; health disparities; safety-net hospital; oncology; pituitary surgery

ABBREVIATIONS ACTH = adrenocorticotropic hormone; $\mathrm{DI}=$ diabetes insipidus; $\mathrm{DVT}=$ deep vein thrombosis; $\mathrm{GH}$ = growth hormone; GTR = gross-total resection; IGF-1 = insulin-like growth factor-1; $\mathrm{PA}=$ pituitary adenoma; $\mathrm{PH}=$ private hospital; $\mathrm{SNH}=$ safety-net hospital; TSH = thyroid-stimulating hormone.

SUBMITTED September 17, 2019. ACCEPTED December 11, 2019.

INCLUDE WHEN CITING Published online February 28, 2020; DOI: 10.3171/2019.12.JNS192506. 
$\mathrm{S}$ OCIODEMOGRAPHIC disparities in healthcare outcomes are well documented in the medical literature. 8,23 , 29,35 Over the past 2 decades, factors such as race, ethnicity, and socioeconomic status have been identified as major barriers to neurosurgical care in the US.11,12,26, 27,31,33 Large retrospective studies using nationwide databases have found that compared to white patients, African American and Hispanic patients have disproportionately less access to high-volume neurosurgical treatment centers, ${ }^{6,11,12,27}$ which is a known predictor of poor neurosurgical outcomes. ${ }^{4,9,10,20,22}$ Disadvantaged groups often present with more advanced disease states and experience delays in obtaining neuro-oncological treatment, particularly postoperative therapies such as chemotherapy and radiation following tumor resection. ${ }^{7,12,32}$ Studies have shown that uninsured patients have worse neurosurgical outcomes compared to their insured counterparts,,${ }^{15,25}$ and African Americans have higher rates of postoperative complications resulting in longer hospital stays and greater healthcare utilization. ${ }^{26,31,33}$

Recent studies have compared neurosurgical outcomes at safety-net hospitals (SNHs) and private hospitals (PHs). One study found that patients with glioblastoma treated at an SNH or those who did not have insurance had higher mortality rates than patients treated at a $\mathrm{PH} .{ }^{5,7}$ According to a recent study at our center, SNH patients with brain metastases treated with stereotactic radiosurgery alone had less follow-up care and a higher rate of poor neurological outcomes than PH patients, ${ }^{14}$ highlighting the importance of considering patient access to follow-up care when deciding on optimal treatment strategies.

Although several studies have investigated sociodemographic barriers to neuro-oncological care in the US, few have looked at disparities in the treatment of pituitary disease. Pituitary adenomas (PAs) are relatively common, with an estimated overall prevalence of $16.7 \% .^{16}$ Although typically benign, PAs can cause profound disability and have significant adverse impacts on quality of life. ${ }^{1}$ One study examined predictors of access to PA resection and found that racial minorities and patients from high-poverty areas were less likely to be admitted to high-volume pituitary centers than were patients from higher income brackets. ${ }^{28}$ However, the effect of sociodemographic disparities on outcomes following resection of PAs is unknown. In this study of patients undergoing PA resection at an $\mathrm{SNH}$ and patients receiving the same treatment at a $\mathrm{PH}$, we compared the clinical presentation, hospital course, and surgical outcome in the 2 patient groups by using a single-surgeon design, with all resections performed by the same attending neurosurgeon and all patients under the care of the same tertiary multidisciplinary team at a single institution.

\section{Methods}

\section{Study Design}

This retrospective cohort study was approved by the institutional review board of the University of Southern California (USC) Keck School of Medicine. Patients were identified from our electronic pituitary tumor database $\left(\right.$ RedCap $\left.{ }^{18}\right)$, which includes information about patient demographics, preoperative symptoms and endocrine status, surgical characteristics, pathology, postoperative course, and follow-up details. We included patients who underwent endoscopic transsphenoidal resection of PAs between January 2015 and December 2017 at a single academic medical institution consisting of one PH (Keck Hospital of USC) and one SNH (Los Angeles County + University of Southern California [LAC+USC] Medical Center) located in Los Angeles, CA. All procedures at both hospitals were performed by the same neurosurgeon (G.Z.).

\section{Imaging Evaluation}

MR imaging was obtained preoperatively and prior to each follow-up visit. The imaging procedure followed standard pituitary protocol, with T1- and T2-weighted images and T1 postcontrast imaging of thin-cut regions of the sella. Dynamic imaging was used in cases of equivocal diagnosis, using a 1-Tesla MRI at the SNH and 1- or 3-Tesla MRI at the PH. Knosp scores were determined in cases of bilateral cavernous sinus invasion, with grade 0 representing no invasion and grade 4 representing total encasement of the carotid artery. Knosp scores are described in detail elsewhere..$^{21,24}$

\section{Surgical Intervention}

All patients underwent endoscopic endonasal approaches via a 2-surgeon binostril technique that has been described in detail elsewhere. ${ }^{34}$ Direct approaches are typically performed by the neurosurgery team at our institutions, with otolaryngology involvement for extended approaches requiring flap reconstruction. Intraoperative CSF leak repair is typically performed with autologous fat and/or fascial repair, with lumbar drainage and pedicled nasoseptal flap reconstruction reserved for extended approaches or high-grade CSF leaks. Patients at both hospitals were approached with the same adherence to standard-of-care principles (e.g., medical therapies for prolactinomas were used as first-line treatment regardless of resource constraints).

\section{Endocrine Evaluation}

Preoperative symptoms were recorded, and endocrine status was determined using serum pituitary laboratory analyses, including serum thyroid-stimulating hormone (TSH), free T4, prolactin, and insulin-like growth factor-1 (IGF-1). Diagnosis of Cushing's disease was made according to the most recent Endocrine Society guidelines, using salivary cortisol and dexamethasone testing. ${ }^{30}$ Acromegaly was defined as serum IGF-1 level above the age-adjusted normal range and growth hormone with lack of suppression below $1 \mathrm{ng} / \mathrm{ml}$, accompanied by signs and symptoms of growth hormone $(\mathrm{GH})$ excess. ${ }^{2}$ Oral glucose tolerance testing was performed in selected equivocal cases. Prolactin values greater than $200 \mathrm{ng} / \mathrm{ml}$ were considered diagnostic of prolactinoma. Serum prolactin levels below $100 \mathrm{ng} / \mathrm{ml}$ were deemed consistent with stalk effect, and values between 100 and $200 \mathrm{ng} / \mathrm{ml}$ were considered consistent with stalk effect in macroadenomas. Panhypopituitarism was defined as $\geq 3$ pituitary axis deficiencies. 
TABLE 1. Comparison of demographic data between patients undergoing PA resection at the $\mathrm{PH}$ versus the SNH

\begin{tabular}{lccc}
\hline & $\mathrm{PH}(\mathrm{n}=92)$ & $\mathrm{SNH}(\mathrm{n}=69)$ & $\mathrm{p} \mathrm{Value}$ \\
\hline $\begin{array}{l}\text { Age in yrs, median } \\
\text { (range) }\end{array}$ & $55.6(21-84)$ & $48.2(16-77)$ & 0.31 \\
\hline $\begin{array}{l}\text { Female sex, \% } \\
\text { Race/ethnicity, } \mathrm{n}(\%)\end{array}$ & 57.6 & 49.3 & 0.30 \\
\hline $\begin{array}{l}\text { Non-Hispanic- } \\
\text { white }\end{array}$ & $36(39.1)$ & $3(4.3)$ & $<0.0001$ \\
\hline Hispanic-any race & $30(32.6)$ & $55(79.7)$ & $<0.0001$ \\
\hline $\begin{array}{l}\text { Asian/Pacific } \\
\text { Islander }\end{array}$ & $17(18.5)$ & $5(7.2)$ & 0.044 \\
\hline \begin{tabular}{l} 
Black \\
\hline Other
\end{tabular} & $2(2.2)$ & $2(2.3)$ & 0.97 \\
\hline $\begin{array}{l}\text { Insurance, } \mathrm{n}(\%) \\
\quad \text { Private/Medicare }\end{array}$ & $82(89.1)$ & $8(11.6)$ & \\
\hline \multicolumn{1}{l}{ Medicaid/uninsured } & $10(10.9)$ & $61(88.4)$ & \\
\hline $\begin{array}{l}\text { Household income in } \\
\text { US\$, mean } \pm \text { SD }\end{array}$ & $63,936 \pm 23,401$ & $49,987 \pm 16,783$ & $<0.0001$ \\
\hline
\end{tabular}

Boldface type indicates statistical significance.

Patient education and consult, and obtaining of consent, were performed in the same manner at both hospitals, with discussion of risks, benefits, need for continual endocrine supplementation, etc. Translators were used at both institutions when indicated.

According to institutional guidelines used at both hospitals, determination of postoperative persistence of disease for Cushing's and acromegaly was based on clinical judgment and supportive laboratory values obtained within 3 months of surgery. Remission of acromegaly in equivocal cases was considered to have occurred after normalization of IGF-1 determined by oral glucose tolerance testing with suppression of GH below $1 \mathrm{ng} / \mathrm{ml}$. Cushing's remission was confirmed by low levels of postoperative cortisol (2-5 ng/dl) after withdrawal of glucocorticoids started during the perioperative timeframe. Surgical remission of prolactinomas was defined as postoperative normalization of prolactin without the need for ongoing medical therapy. Remission for nonfunctional tumors was based on radiographic imaging.

Follow-up was conducted with the surgeon at 1 week postoperatively, at 6 weeks with hormonal analysis as indicated, and at 3 months with MRI, visual fields, and hormonal testing as indicated. Further discussion of followup methodology is discussed in the Limitations section.

Laboratory tests performed at both $\mathrm{PH}$ and $\mathrm{SNH}$ were sent to Quest Diagnostics.

\section{Statistical Analysis}

Patient demographics, presenting symptomatology, preoperative endocrine status, surgical characteristics, postoperative course, and follow-up details were reviewed. Comparisons were made using Pearson's chi-square test for categorical variables and a two-tailed t-test or MannWhitney U-test for continuous variables, with an alpha
TABLE 2. Comparison of presenting symptoms in PH versus SNH patients

\begin{tabular}{lccl}
\hline \multicolumn{1}{c}{ Symptoms } & $\mathrm{PH}$ & $\mathrm{SNH}$ & $\mathrm{p}$ Value \\
\hline Headache & $42(45.7)$ & $47(68.1)$ & $\mathbf{0 . 0 0 5 5}$ \\
\hline Vision loss & $33(35.9)$ & $44(63.8)$ & $\mathbf{0 . 0 0 1 1}$ \\
\hline Decreased libido & $15(16.3)$ & $6(8.7)$ & 0.16 \\
\hline Amenorrhea* & $15(28.3)$ & $9(26.4)$ & 0.56 \\
\hline Galactorrhea & $9(9.8)$ & $2(2.9)$ & 0.087 \\
\hline Fatigue & $32(34.8)$ & $9(13.0)$ & $\mathbf{0 . 0 0 2 2}$ \\
\hline Cranial nerve palsy & $5(5.4)$ & $4(5.8)$ & 0.91 \\
\hline Acromegaly & $19(20.7)$ & $14(20.3)$ & 0.95 \\
\hline Cushing's disease & $4(4.3)$ & $3(4.3)$ & 1.00 \\
\hline Incidental finding & $7(7.6)$ & $4(5.8)$ & 0.66 \\
\hline Pituitary apoplexy & $7(7.6)$ & $13(18.8)$ & $\mathbf{0 . 0 3 3}$ \\
\hline
\end{tabular}

SNH patients presented with higher rates of headache, visual loss, fatigue, and pituitary apoplexy. Values are presented as number of patients (\%) unless otherwise indicated. Boldface type indicates statistical significance.

${ }^{*}$ Female patients only.

level of 0.05 . Household incomes were based on selfreported zip codes and aggregate zip code data from the 2016 American Community Survey.

\section{Results}

\section{Baseline Patient Demographics}

In total, 170 patients, including $95 \mathrm{PH}$ patients (56\%) and $75 \mathrm{SNH}$ patients (44\%), underwent transsphenoidal PA resection during the period from January 2015 to December 2017. Three PH patients (3\%) and $6 \mathrm{SNH}$ patients $(8 \%)$ were excluded due to lack of preoperative data, resulting in a total of 161 patients $(92 \mathrm{PH}$ patients and 69 SNH patients) analyzed.

Demographic comparisons between the 2 hospitals are shown in Table 1. The median age for $\mathrm{PH}$ patients was 55.6 years (range 21-84 years) compared to 48.2 years (range $16-77$ years) in SNH patients $(\mathrm{p}=0.31)$. In the SNH cohort, $4.3 \%$ of patients were non-Hispanic white, compared to $39 \%$ of patients in the $\mathrm{PH}$ cohort ( $\mathrm{p}<0.0001$ ); conversely, $79.7 \%$ of SNH patients were Hispanic (any race), compared to $32.6 \%$ of $\mathrm{PH}$ patients ( $\mathrm{p}<0.0001$ ). A significantly higher percentage of SNH patients compared to $\mathrm{PH}$ patients were uninsured or on MediCal (Medicaid), $(88.4 \%$ vs $11.6 \%, \mathrm{p}<0.0001)$. SNH patients had a lower median household income than $\mathrm{PH}$ patients $(\$ 49,987 \pm \$ 16,783$ vs $\$ 63,936 \pm \$ 23,401, \mathrm{p}<0.0001)$.

Symptoms at clinical presentation and preoperative endocrine status of patients at both hospitals are shown in Tables 2 and 3, respectively. Compared to PH patients, SNH patients presented with higher rates of headache (68.1\% vs $45.7 \%, \mathrm{p}=0.0048)$, vision loss $(63.8 \%$ vs $35.9 \%$, $\mathrm{p}<0.0005)$, and pituitary apoplexy $(18.8 \%$ vs $7.6 \%$, p < $0.0334)$. PH patients presented with a higher rate of selfreported fatigue than $\mathrm{SNH}$ patients $(34.8 \%$ vs $13.0 \%, \mathrm{p}=$ $0.0017)$. In terms of endocrine status, SNH patients presented with a higher rate of preoperative panhypopituitarism $(18.8 \%$ vs $4.3 \%, \mathrm{p}=0.0031)$, and $\mathrm{PH}$ patients pre- 
TABLE 3. Preoperative endocrine status of PH versus SNH patients

\begin{tabular}{lccl}
\hline \multicolumn{1}{c}{ Endocrine Status } & $\mathrm{PH}$ & $\mathrm{SNH}$ & $\mathrm{p}$ Value \\
\hline Hyperprolactinemia & $22(23.9)$ & $9(13.0)$ & 0.083 \\
\hline Hypocortisolemia & $5(5.4)$ & $6(8.7)$ & 0.41 \\
\hline Hypogonadism & $36(39.1)$ & $16(23.2)$ & $\mathbf{0 . 0 3 2}$ \\
\hline Hypothyroidism & $18(19.6)$ & $14(20.3)$ & 0.91 \\
\hline Acromegaly & $18(19.6)$ & $12(17.4)$ & 0.72 \\
\hline Cushing's disease & $4(4.3)$ & $3(4.3)$ & 1.00 \\
\hline Panhypopituitarism* & $4(4.3)$ & $13(18.8)$ & $\mathbf{0 . 0 0 3 1}$ \\
\hline Normal & $20(21.7)$ & $15(21.7)$ & 1.00 \\
\hline
\end{tabular}

SNH patients had a significantly higher rate of panhypopituitarism than $\mathrm{PH}$ patients. Values are presented as number of patients (\%) unless otherwise indicated. Boldface type indicates statistical significance.

* Panhypopituitarism was considered an independent category (e.g., there were $4 \mathrm{PH}$ patients and $13 \mathrm{SNH}$ patients with panhypopituitarism in addition to the $\mathrm{PH}$ and $\mathrm{SNH}$ patients with hypocortisolemia).

sented with a higher rate of documented hypogonadism $(39.1 \%$ vs $23.2 \%, \mathrm{p}=0.0320)$.

\section{Baseline Tumor Characteristics}

Tumor characteristics are reported in Table 4. SNH patients had a significantly larger mean tumor diameter than PA patients $(26.2 \pm 11.2$ vs $22.4 \pm 11.2 \mathrm{~mm}, \mathrm{p}=0.0347)$. There was no significant difference in the percentage of patients who presented with any cavernous sinus invasion (33.7\% of PH vs $40.6 \%$ of SNH patients, $\mathrm{p}=0.4388$ ); however, SNH patients presented with a significantly higher rate of bilateral cavernous sinus invasion $(\mathrm{n}=9,13 \%)$ compared to PH patients $(\mathrm{n}=4,4.3 \%, \mathrm{p}=0.0451)$. Of the patients who had cavernous sinus invasion, the mean Knosp score for SNH patients was 2.5, versus 2.7 for $\mathrm{PH}$ patients $(\mathrm{p}=0.345)$. Further analysis by chi-square test of differences in Knosp score among patients with cavernous sinus invasion with scores of 3 and 4 grouped together showed no significant difference in Knosp score between the cohorts $(\mathrm{p}=0.1815)$.

\section{Surgical Resection}

Resection of tumor was performed by the same neurosurgeon at both the SNH and PH. Surgical characteristics and outcomes are reported in Table 4. Rates of gross-total resection (GTR), assessed by postoperative MRI at 3 months, were similar between the groups (PH $76.1 \%$ GTR, SNH 73.9\% GTR, $p=0.7499$ ). There was a significantly higher rate of intraoperative CSF leak in the $\mathrm{PH}$ cohort compared to the SNH group (37\% vs $22 \%, \mathrm{p}=$ 0.037). Eleven SNH patients (15.7\%) underwent follow-up stereotactic radiosurgery or other radiation, compared to 4 (4.34\%) $\mathrm{PH}$ patients $(\mathrm{p}=0.014)$.

\section{Tumor Pathology}

Tumor pathology is reported in Table 5. Nonfunctional PAs represented the majority of cases in both $\mathrm{PH}$ patients (62 [67.4\%] vs 46 [66.7\%], $\mathrm{p}=0.92]$. The second most common tumors were GH-secreting somatotrophic ade-
TABLE 4. Surgical and tumor characteristics of PH versus SNH patients

\begin{tabular}{|c|c|c|c|}
\hline & $\mathrm{PH}$ & SNH & $\mathrm{p}$ Value \\
\hline Reoperation* & $16(17.4)$ & $10(14.5)$ & 0.62 \\
\hline Macroadenoma at presentation & $83(90.2)$ & $66(95.7)$ & 0.19 \\
\hline Giant adenoma† & $9(9.8)$ & $7(10.1)$ & 0.95 \\
\hline $\begin{array}{l}\text { Max tumor diameter in } \mathrm{mm} \text {, } \\
\text { mean } \pm \mathrm{SD}\end{array}$ & $22.4 \pm 11.2$ & $26.2 \pm 11.2$ & 0.035 \\
\hline Tumor invasion & $70(76.1)$ & $56(81.2)$ & 0.44 \\
\hline Cavernous sinus & $30(33.7)$ & $28(40.6)$ & 0.37 \\
\hline Right & $16(17.4)$ & $12(17.4)$ & 1.00 \\
\hline Left & $10(10.9)$ & $7(10.1)$ & 0.87 \\
\hline Bilateral & $4(4.3)$ & $9(13.0)$ & 0.045 \\
\hline Suprasellar & $52(56.5)$ & $39(56.5)$ & 1.00 \\
\hline Infrasellar & $16(17.4)$ & $8(11.6)$ & 0.31 \\
\hline Sinus & $14(15.2)$ & $5(7.2)$ & 0.12 \\
\hline Clivus & $7(7.6)$ & $8(11.6)$ & 0.39 \\
\hline Ventricle & $1(1.1)$ & $1(1.4)$ & 0.87 \\
\hline $\begin{array}{l}\text { Cavernous sinus invasion, } \\
\text { Knosp score }\end{array}$ & & & $0.18 \ddagger$ \\
\hline Mean & 2.7 & 2.5 & \\
\hline 1 & 5 & 1 & \\
\hline 2 & 6 & 7 & \\
\hline $3 / 4$ & 20 & 15 & \\
\hline Postop GTR & 70 (76.1) & 51 (73.9) & 0.75 \\
\hline Intraop CSF leak & $34(37.0)$ & $15(21.7)$ & 0.037 \\
\hline
\end{tabular}

SNH patients had significantly larger tumors and significantly lower rates of intraoperative GTR and intraoperative CSF leak. Values are presented as number of patients (\%) unless otherwise indicated. Boldface type indicates statistical significance.

* Percentage of patients from each cohort who were undergoing a second operation.

† Tumor diameter $\geq 4 \mathrm{~cm}$.

$\ddagger$ Pearson's chi-square test comparing proportions of patients with Knosp scores of 1,2 , and 3 and 4 combined.

nomas, comprising $19.6 \%(\mathrm{n}=18)$ of the $\mathrm{PH}$ group tumors versus $18.8 \%(\mathrm{n}=13)$ of the $\mathrm{SNH}$ group tumors $(\mathrm{p}=0.89)$. Prolactinomas represented 5.4\% $(n=5)$ of tumors resected at the $\mathrm{PH}$, versus $2.9 \%(\mathrm{n}=2)$ of tumors resected at the SNH $(\mathrm{p}=0.44)$. There were 4 adrenocorticotropic hormone $(\mathrm{ACTH})$-secreting tumors in the $\mathrm{PH}$ patients $(4.3 \%)$ versus $3(4.3 \%)$ in the $\mathrm{SNH}$ patients $(\mathrm{p}=1)$. There were 2 TSH-secreting adenomas in the PH patients (2.2\%) and zero in the $\mathrm{SNH}$ patients.

\section{Surgical Complications and Immediate Outcomes}

There were no significant differences in complication rates between the 2 groups, as shown in Table 6. There were 5 cases of CSF leak requiring reoperation or lumbar drain in each group (5.4\% vs $7.2 \%$ in the $\mathrm{PH}$ vs $\mathrm{SNH}$ group, respectively, $\mathrm{p}=0.64$ ). There were 6 cases of hyponatremia at the $\mathrm{PH}$ group versus 1 in the $\mathrm{SNH}$ group (6.5\% vs $1.4 \%, \mathrm{p}=0.11)$. There were 8 cases of transient diabetes insipidus (DI) in the PH group versus 6 in the 
TABLE 5. Pathologically confirmed tumor subtypes in PH and SNH patients

\begin{tabular}{lccc}
\hline PA Subtype & $\mathrm{PH}$ & $\mathrm{SNH}$ & $\mathrm{p}$ Value \\
\hline ACTH & $4(4.3)$ & $3(4.3)$ & $>0.99$ \\
\hline GH & $18(19.6)$ & $13(18.8)$ & 0.89 \\
\hline GH and PRL & $1(1.1)$ & $1(1.4)$ & 0.86 \\
\hline TSH & $2(2.2)$ & $0(0)$ & \\
\hline Prolactinoma & $5(5.4)$ & $2(2.9)$ & 0.44 \\
\hline NFPA & $62(67.4)$ & $46(66.7)$ & 0.92 \\
\hline
\end{tabular}

$\mathrm{NFPA}=$ nonfunctional pituitary adenoma; $\mathrm{PRL}=$ prolactin

Values are presented as number of patients (\%) unless otherwise indicated.

SNH group $(8.7 \%$ vs $8.6 \%, p=0.98)$. There was 1 case of each the following: deep vein thrombosis (DVT; SNH group), permanent DI (SNH group), and abdominal hematoma (PH group). There was 1 case of hydrocephalus in each group. There were 2 cases of hematoma, 1 case of stroke, and 2 cases of sinusitis in the $\mathrm{PH}$ group, but none of these complications occurred in the SNH group. There were no deaths in either group.

There was no significant difference between the 2 groups in rates of early readmission $(15.2 \%$ in the $\mathrm{PH}$ vs $12.9 \%$ in the $\mathrm{SNH}$ group, $\mathrm{p}=0.71$ ) or in rates of reoperation $(7.6 \%$ in the $\mathrm{PH}$ vs $4.3 \%$ in the $\mathrm{SNH}$ group, $\mathrm{p}=$ 0.38). PH patients had a median postoperative length of stay of 2 days compared to 3 days for the SNH patients ( $p$ $=0.5099$ ).

\section{Postoperative Outcomes}

Follow-up data are presented in Table 7. Mean follow-up times were 13.9 months for PH patients and 13.4 months for SNH patients. Seven (7.6\%) PH patients were lost to follow-up versus $13(18.6 \%)$ SNH patients $(\mathrm{p}=$ 0.04). Of those patients with adequate follow-up, $89 \%$ of $\mathrm{PH}$ patients achieved postoperative improvement in headache, versus $80 \%$ of SNH patients $(\mathrm{p}=0.14)$. SNH patients and $\mathrm{PH}$ patients achieved similar rates of postoperative improvement in vision (82\% SNH vs $84 \% \mathrm{PH}, \mathrm{p}=0.74$ ), based on patient self-assessment and formal visual field testing.

$\mathrm{PH}$ patients demonstrated improved endocrine outcomes in $47 \%$ of cases, versus $17 \%$ of cases in $\mathrm{SNH}$ patients $(\mathrm{p}<0.0001)$. For hyperfunctioning adenomas, improved endocrine status was defined as hormonal remission without the need for medications postoperatively. Of patients with prolactinomas, 3 out of $5 \mathrm{PH}$ patients required cabergoline postoperatively compared to 2 out of 2 SNH patients. For ACTH-secreting adenomas, 1 patient at each hospital required postoperative medication. For GHsecreting adenomas, 3 out of 15 cases (20\%) in PH patients required postoperative somatostatin analog medications compared to 4 out of 9 (44\%) cases in SNH patients.

Postoperative hypopituitarism was identified by either follow-up endocrine laboratory tests or persistence of symptoms requiring hormone supplementation. Of patients with preoperative hypogonadism, 12 out of 16 cases (75\%) in SNH patients persisted compared to 10 out of 36 cases $(28 \%)$ in PH patients. There were no new cases of hypogonadism reported postoperatively. Of patients

TABLE 6. Postoperative complications in SNH versus PH patients

\begin{tabular}{|c|c|c|c|c|}
\hline Complication & $\mathrm{PH}$ & SNH & $p$ Value & Risk Difference $(95 \% \mathrm{Cl})$ \\
\hline CSF leak & $5(5.4)$ & $5(7.2)$ & 0.64 & $-1.8 \%(-0.09$ to 0.06$)$ \\
\hline Hyponatremia & $6(6.5)$ & $1(1.4)$ & 0.11 & $5.1 \%(-0.01$ to 0.11$)$ \\
\hline DI, transient & $8(8.7)$ & $6(8.6)$ & 0.98 & $0.1 \%(-0.09$ to 0.09$)$ \\
\hline DI, permanent & $0(0.0)$ & $1(1.4)$ & & $-1.4 \%(-0.04$ to 0.01$)$ \\
\hline Meningitis & $1(1.1)$ & $1(1.4)$ & 0.24 & $-0.3 \%(-0.04$ to 0.03$)$ \\
\hline Sinusitis & $2(2.2)$ & 0 & & $2.2 \%(-0.01$ to 0.05$)$ \\
\hline Bacteremia/sepsis & $1(1.1)$ & 0 & & $1.1 \%(-0.01$ to 0.03$)$ \\
\hline Pneumonia & 0 & $1(1.4)$ & & $-1.4 \%(-0.04$ to 0.01$)$ \\
\hline DVT & 0 & $1(1.4)$ & & $-1.4 \%(-0.04$ to 0.01$)$ \\
\hline Abdominal hematoma & $1(1.1)$ & 0 & & $1.1 \%(-0.01$ to 0.03$)$ \\
\hline Visual loss & 0 & 0 & & \\
\hline Epistaxis & $2(2.2)$ & $2(2.9)$ & 0.77 & $-0.7 \%(-0.06$ to 0.04$)$ \\
\hline Cranial nerve palsy & 0 & 0 & & \\
\hline Hematoma & $2(2.2)$ & 0 & & $2.2 \%(-0.01$ to 0.05$)$ \\
\hline Stroke & 1 & 0 & & $1 \%(-0.01$ to 0.03$)$ \\
\hline Carotid artery injury & 0 & 0 & & \\
\hline Hydrocephalus & $1(1.1)$ & $1(1.4)$ & & $-0.3 \%(-0.04$ to 0.03$)$ \\
\hline Death & 0 & 0 & & \\
\hline Other & $4(4.3)$ & $3(4.3)$ & 1 & \\
\hline None & $65(70.7)$ & $55(78.6)$ & 0.27 & $-7.9 \%(-0.21$ to 0.06$)$ \\
\hline
\end{tabular}

There were no significant differences in rates of complications between the 2 groups. 
TABLE 7. Long-term headache and visual and endocrine outcomes during follow-up after PA resection

\begin{tabular}{|c|c|c|c|}
\hline & $\mathrm{PH}$ & $\mathrm{SNH}$ & p Value \\
\hline \multicolumn{4}{|l|}{ Headache } \\
\hline Improved & $89 \%$ & $80 \%$ & 0.14 \\
\hline Stable & $11 \%$ & $18 \%$ & 0.25 \\
\hline Worse & $0.0 \%$ & $2.0 \%$ & \\
\hline No. of patients & 84 & 52 & \\
\hline \multicolumn{4}{|l|}{ Visual outcomes } \\
\hline Improved & $84 \%$ & $82 \%$ & 0.74 \\
\hline Stable & $16 \%$ & $18 \%$ & 0.75 \\
\hline Worse & $0 \%$ & $2.0 \%$ & \\
\hline No. of patients & 85 & 58 & \\
\hline \multicolumn{4}{|l|}{ Endocrine outcomes } \\
\hline Improved & $47 \%$ & $17 \%$ & $<0.0001$ \\
\hline Stable & $48 \%$ & $65 \%$ & 0.04 \\
\hline \multicolumn{4}{|c|}{ Panhypopituitarism } \\
\hline All & $10 \%$ & $23 \%$ & 0.04 \\
\hline New & $5.5 \%$ & $5.6 \%$ & 0.98 \\
\hline No. of patients* & 72 & 53 & \\
\hline
\end{tabular}

Improved outcomes represent patients with preoperative deficits that were self-reportedly improved postoperatively. SNH patients had lower rates of improved endocrine outcomes. See the Postoperative Outcomes section for more endocrinopathy results. Boldface type indicates statistical significance. * Patients with perioperative endocrinopathies.

with preoperative hypocortisolemia, 3 out of 6 cases persisted in SNH patients compared to 2 out of 5 cases in $\mathrm{PH}$ patients. There were 13 new cases of hypocortisolemia in SNH patients compared to 6 new cases in PH patients. SNH patients as a cohort had a higher rate of postoperative panhypopituitarism than $\mathrm{PH}$ patients (23\% vs $10 \%$, p $=0.046$ ), although this outcome was driven by a higher degree of preoperative panhypopituitarism. In patients with preoperative panhypopituitarism, it persisted in 9 out of 13 (69\%) SNH patients compared to 3 out of 4 (75\%) PH patients. There were 3 new cases of panhypopituitarism in SNH patients compared to 4 new cases in PH patients $(\mathrm{p}=0.98)$. Patients with postoperative isolated hypocortisolemia or panhypopituitarism required long-term steroids. There was no statistical difference in rates of tumor recurrence or progression over the follow-up period $(3.5 \%$ $[\mathrm{PH}]$ vs $6.7 \%[\mathrm{SNH}], \mathrm{p}=0.38)$.

\section{Discussion}

Patients with PAs who receive surgical treatment at an SNH are of lower socioeconomic status; present with larger, more advanced and invasive PAs; and have a higher propensity for headaches, vision loss, endocrinopathy, and pituitary apoplexy. Postoperatively, both cohorts had similar overall postoperative courses and complication profiles, with a comparable rate of resection despite the higher rates of more advanced disease in SNH patients. Despite barriers to diagnosis and care of patients with advanced PA disease, safe and durable outcomes were achieved in both cohorts by providing similar multidisciplinary neurosurgical and endocrinological care teams for both the $\mathrm{SNH}$ and $\mathrm{PH}$ patients. All patients at both sites were managed by the same teams of neurosurgeons and endocrinologists, and all cases were reviewed in a weekly multidisciplinary pituitary tumor board conference. Our conclusion is that a tertiary multidisciplinary care approach can partially mitigate the obvious disparities in presentation and clinical and imaging findings of advanced disease encountered in the public SNH compared with the $\mathrm{PH}$ setting.

Literature involving the impact of sociodemographic status on outcomes following pituitary neurosurgery remains sparse. SNHs serve poorer, underinsured patients. As a result of limited access to care, patients present with more advanced pathology, which our data demonstrate, as SNH patients had higher rates of headache and visual loss, which are symptoms of mass effect, more advanced endocrinopathies, and larger mean tumor diameter. Jahangiri et al. suggested a relationship between lower socioeconomic status and pituitary apoplexy ${ }^{19}$ A similar association was seen in our study, in that SNH patients had a significantly lower median household income (socioeconomic status) and corresponding higher rate of pituitary apoplexy upon presentation.

In terms of the relationship between sociodemographic identifiers and outcomes, data from the National Inpatient Sample showed that in patients undergoing uncomplicated transsphenoidal surgery for PA resection, lower median income and Hispanic ethnicity were factors that drove longer hospital lengths of stay. ${ }^{17}$ Our data did not demonstrate these trends; SNH patients had a significantly lower median income, and a significantly higher percentage of patients were Hispanic, but they experienced lengths of stay similar to those of $\mathrm{PH}$ patients. Perhaps one explanation for this trend, or lack thereof, is due to both the SNH and PH in our study being high-volume hospitals. Barker et al. have asserted that higher-volume hospitals and surgeons correlate with superior short-term outcomes for pituitary neurosurgery, and this trend has been demonstrated for other neurosurgical pathologies as well.,3,4

Rates of GTR and subsequent long-term outcomes were also similar in both of our study groups. In terms of headache and visual loss, there were similar rates of symptom improvement (between those in both groups who presented with headache and vision loss) postoperatively ( $p=0.14$ and 0.74 , respectively). This finding implies that surgical intervention can lead to dramatic improvements in quality of life that are distributed relatively equally throughout sociodemographic strata. However, SNH patients had worse endocrine outcomes, suggesting that the perceived similar rates of symptomatic improvement may be due to differences in reporting between the 2 groups.

Recurrence rates demonstrated no significant differences between SH and PH patients $(p=0.67)$ over the relatively short follow-up period. This finding can be partially attributed to the generally slow-growing nature of pituitary tumors.$^{13}$ However, this analysis has information from just over 1 year of follow-up. A larger, longer-term study is needed to determine what environmental factors put patients at risk for recurrence. 


\section{Future Directions}

Our data suggest that while lack of insurance, low socioeconomic status, and Hispanic ethnicity are all correlated with more advanced disease progression, these factors are potentially mitigated by surgery being performed by an experienced surgeon at a high-volume center. The differences between high-volume centers and lower-volume centers and PA resection outcomes should be further explored to determine specific features associated with optimal quality of care.

As the field of neurosurgery continues to explore the effects of sociodemographic factors on outcomes, the role of primary care must be equally explored. Chandra and colleagues have discussed the impact of primary care providers in early diagnosis and continued care of glioblastoma ${ }^{7}$; the role of primary care providers is equally important in the management of PAs. Our SNH patients had a higher rate of endocrinopathy on presentation, and as a result many of them were on long-term endocrine therapy at the time of this report. Similarly, with regard to perioperative endocrine status, rates of hypogonadism were higher in the $\mathrm{PH}$ patients. We consider this finding to be due to ascertainment bias; patients at the $\mathrm{PH}$ are more likely to receive an endocrine workup that results in documentation/treatment of hypogonadism and are more likely to have had extensive endocrine workups prior to seeing a specialist at a tertiary center. These biases are likely not well captured within our model and represent a future direction of research. The role of primary care providers in diagnosing these tumors early could potentially save some pituitary function and ultimately improve quality of life. In addition, it is important for the field of neurosurgery to identify the causes of potential systematic disparities between groups of patients. In our cohort specifically, many of the differences seen in presentation are largely due to lack of engagement with the healthcare system. This disengagement is multifactorial; it results from a lack of insurance, language barriers between patients and providers, general mistrust of Western healthcare, and-particularly important in a cohort with low socioeconomic status-the fact that the hours required to see a doctor largely take away from work hours in patients who may not receive paid sick leave.

\section{Limitations}

Our study has several limitations. In addition to the inherent limitations of a retrospective study, the majority of $\mathrm{PH}$ patients undergoing PA resection were undergoing elective procedures, whereas many of the SNH patients were admitted from the emergency room-accordingly, the circumstances by which preoperative symptoms were recorded were not entirely equal. Lastly, a larger portion of SNH patients were lost to follow-up, and thus the longterm outcome data may not be truly representative of the entire cohort. It is important to note that follow-up at the 2 institutions varies widely. At the $\mathrm{PH}$, there is an established pituitary center with protocols that provide consistency in follow-up care. Conversely, SNH patients are followed separately by individual neurosurgery and endocrinology clinics that are staffed by various attending physicians with no set protocol followed. Both hospitals have equal operative resources (imaging, staff, technology, etc.) for PA resection as part of a concerted effort to build the SNH into a tertiary pituitary center. As a result, the external validity and generalizability of this study may be limited as other SNHs may not have the equivalent resources necessary to care for similarly complex pathologies.

\section{Conclusions}

Our study is to our knowledge the first to compare clinical characteristics and outcomes of PA resection in a PH setting versus an SNH setting when the patients in both groups are cared for by similar multidisciplinary teams, with a single-surgeon model, at academic hospitals. The single-surgeon design of our study allowed us to uniquely examine the effects of sociodemographic variables on presentation and outcome. We show that SNH patients present with significantly more advanced disease states and lower socioeconomic status but ultimately have similar short-term and midterm outcomes, demonstrating that an experienced surgical and endocrine team working together at a high-volume academic center may partially mitigate against factors that historically portend negative outcomes in PA patients.

\section{References}

1. Andela CD, Scharloo M, Pereira AM, Kaptein AA, Biermasz NR: Quality of life (QoL) impairments in patients with a pituitary adenoma: a systematic review of QoL studies. Pituitary 18:752-776, 2015

2. Arafat AM, Möhlig M, Weickert MO, Perschel FH, Purschwitz J, Spranger J, et al: Growth hormone response during oral glucose tolerance test: the impact of assay method on the estimation of reference values in patients with acromegaly and in healthy controls, and the role of gender, age, and body mass index. J Clin Endocrinol Metab 93:1254-1262, 2008

3. Barker FG II, Curry WT Jr, Carter BS: Surgery for primary supratentorial brain tumors in the United States, 1988 to 2000: the effect of provider caseload and centralization of care. Neuro Oncol 7:49-63, 2005

4. Barker FG II, Klibanski A, Swearingen B: Transsphenoidal surgery for pituitary tumors in the United States, 1996-2000: mortality, morbidity, and the effects of hospital and surgeon volume. J Clin Endocrinol Metab 88:4709-4719, 2003

5. Brandel MG, Rennert RC, Lopez Ramos C, Santiago-Dieppa DR, Steinberg JA, Sarkar RR, et al: Management of glioblastoma at safety-net hospitals. J Neurooncol 139:389-397, 2018

6. Brucker-Davis F, Oldfield EH, Skarulis MC, Doppman JL, Weintraub BD: Thyrotropin-secreting pituitary tumors: diagnostic criteria, thyroid hormone sensitivity, and treatment outcome in 25 patients followed at the National Institutes of Health. J Clin Endocrinol Metab 84:476-486, 1999

7. Chandra A, Rick JW, Dalle Ore C, Lau D, Nguyen AT, Carrera $\mathrm{D}$, et al: Disparities in health care determine prognosis in newly diagnosed glioblastoma. Neurosurg Focus 44(6):E16, 2018

8. Chen J, Vargas-Bustamante A, Mortensen K, Ortega AN: Racial and ethnic disparities in health care access and utilization under the Affordable Care Act. Med Care 54:140-146, 2016

9. Chernov MF: The impact of provider volume on mortality after intracranial tumor resection and outcome and cost of craniotomy performed to treat tumors in regional academic referral centers. Neurosurgery 54:1027-1028, 2004

10. Cowan JA Jr, Dimick JB, Leveque JC, Thompson BG, Up- 
church GR Jr, Hoff JT: The impact of provider volume on mortality after intracranial tumor resection. Neurosurgery 52:48-54, 2003

11. Curry WT Jr, Barker FG II: Racial, ethnic and socioeconomic disparities in the treatment of brain tumors. J Neurooncol 93:25-39, 2009

12. Curry WT Jr, Carter BS, Barker FG II: Racial, ethnic, and socioeconomic disparities in patient outcomes after craniotomy for tumor in adult patients in the United States, 19882004. Neurosurgery 66:427-438, 2010

13. Dekkers OM, Hammer S, de Keizer RJ, Roelfsema F, Schutte PJ, Smit JW, et al: The natural course of non-functioning pituitary macroadenomas. Eur J Endocrinol 156:217-224, 2007

14. Diao K, Sun Y, Yoo SK, Yu C, Ye JC, Trakul N, et al: Safety-net versus private hospital setting for brain metastasis patients treated with radiosurgery alone: disparities in followup care and outcomes. Cancer 124:167-175, 2018

15. El-Sayed AM, Ziewacz JE, Davis MC, Lau D, Siddiqi HK, Zamora-Berridi GJ, et al: Insurance status and inequalities in outcomes after neurosurgery. World Neurosurg 76:459466, 2011

16. Ezzat S, Asa SL, Couldwell WT, Barr CE, Dodge WE, Vance ML, et al: The prevalence of pituitary adenomas: a systematic review. Cancer 101:613-619, 2004

17. Hamill CS, Villwock JA, Sykes KJ, Chamoun RB, Beahm $\mathrm{DD}$ : Socioeconomic factors affecting discharge status of patients with uncomplicated transsphenoidal adenohypophysectomy. J Neurol Surg B Skull Base 79:501-507, 2018

18. Harris PA, Taylor R, Thielke R, Payne J, Gonzalez N, Conde JG: Research electronic data capture (REDCap) - a metadata-driven methodology and workflow process for providing translational research informatics support. J Biomed Inform 42:377-381, 2009

19. Jahangiri A, Potts M, Kunwar S, Blevins L, El-Sayed IH, Aghi MK: Extended endoscopic endonasal approach for suprasellar Rathke's cleft cysts. J Clin Neurosci 21:779-785, 2014

20. Johnston SC: Effect of endovascular services and hospital volume on cerebral aneurysm treatment outcomes. Stroke 31:111-117, 2000

21. Knosp E, Steiner E, Kitz K, Matula C: Pituitary adenomas with invasion of the cavernous sinus space: a magnetic resonance imaging classification compared with surgical findings. Neurosurgery 33:610-618, 1993

22. Long DM, Gordon T, Bowman H, Etzel A, Burleyson G, Betchen S, et al: Outcome and cost of craniotomy performed to treat tumors in regional academic referral centers. Neurosurgery 52:1056-1065, 2003

23. Manuel JI: Racial/ethnic and gender disparities in health care use and access. Health Serv Res 53:1407-1429, 2018

24. Micko AS, Wöhrer A, Wolfsberger S, Knosp E: Invasion of the cavernous sinus space in pituitary adenomas: endoscopic verification and its correlation with an MRI-based classification. J Neurosurg 122:803-811, 2015

25. Momin EN, Adams H, Shinohara RT, Frangakis C, Brem H, Quiñones-Hinojosa A: Postoperative mortality after surgery for brain tumors by patient insurance status in the United States. Arch Surg 147:1017-1024, 2012

26. Mukherjee D, Patil CG, Todnem N, Ugiliweneza B, Nuño M, Kinsman M, et al: Racial disparities in Medicaid patients after brain tumor surgery. J Clin Neurosci 20:57-61, 2013
27. Mukherjee D, Zaidi HA, Kosztowski T, Chaichana KL, Brem $\mathrm{H}$, Chang DC, et al: Disparities in access to neuro-oncologic care in the United States. Arch Surg 145:247-253, 2010

28. Mukherjee D, Zaidi HA, Kosztowski T, Chaichana KL, Salvatori R, Chang DC, et al: Predictors of access to pituitary tumor resection in the United States, 1988-2005. Eur J Endocrinol 161:259-265, 2009

29. Nelson A: Unequal treatment: confronting racial and ethnic disparities in health care. J Natl Med Assoc 94:666-668, 2002

30. Nieman LK, Biller BM, Findling JW, Newell-Price J, Savage MO, Stewart PM, et al: The diagnosis of Cushing's syndrome: an Endocrine Society Clinical Practice Guideline. J Clin Endocrinol Metab 93:1526-1540, 2008

31. Nuño M, Mukherjee D, Elramsisy A, Nosova K, Lad SP, Boakye M, et al: Racial and gender disparities and the role of primary tumor type on inpatient outcomes following craniotomy for brain metastases. Ann Surg Oncol 19:2657-2663, 2012

32. Pollom EL, Fujimoto DK, Han SS, Harris JP, Tharin SA, Soltys SG: Newly diagnosed glioblastoma: adverse socioeconomic factors correlate with delay in radiotherapy initiation and worse overall survival. J Radiat Res (Tokyo) 59 (Suppl 1):i11-i18, 2018

33. Schiraldi M, Patil CG, Mukherjee D, Ugiliweneza B, Nuño M, Lad SP, et al: Effect of insurance and racial disparities on outcomes in traumatic brain injury. J Neurol Surg A Cent Eur Neurosurg 76:224-232, 2015

34. Takemura M, Fujimoto Y, Kobayashi T, Komori M, Stamm AC, Vellutini E, et al: A modified combined transseptal/ transnasal binostril approach for pituitary lesions in patients with a narrow nasal space: technical note. Neurol Med Chir (Tokyo) 54:622-628, 2014

35. US Department of Health and Human Services: National Healthcare Disparities Report, 2004. (https://archive.ahrq. gov/qual/nhdr04/nhdr04.htm) [Accessed January 3, 2020]

\section{Disclosures}

The authors report no conflict of interest concerning the materials or methods used in this study or the findings specified in this paper.

\section{Author Contributions}

Conception and design: Cyprich, Pangal, Zada. Acquisition of data: Cyprich, Pangal, Shiroishi, Liu. Analysis and interpretation of data: all authors. Drafting the article: Cyprich, Pangal. Critically revising the article: Cyprich, Pangal, Rutkowski, Donoho, Carmichael, Zada. Reviewed submitted version of manuscript: all authors. Approved the final version of the manuscript on behalf of all authors: Cyprich. Statistical analysis: Cyprich, Pangal.

\section{Supplemental Information}

\section{Previous Presentations}

The abstract was included as a poster presentation at the American Association of Neurological Surgeons Annual Meeting on April 13-17, 2019, in San Diego, CA.

\section{Correspondence}

Janelle Cyprich: Keck School of Medicine of USC, Los Angeles, CA. cyprich@usc.edu. 